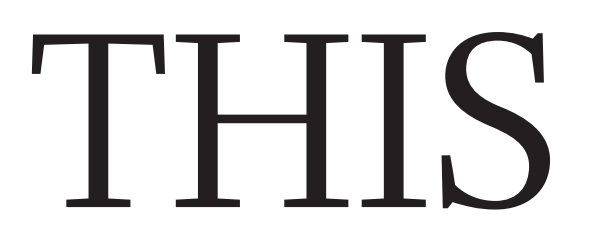

EDITORIALS
NEW DEAL Welcome the growing band of venture philanthropists $\mathbf{p . 2 6 6}$

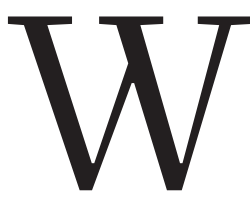

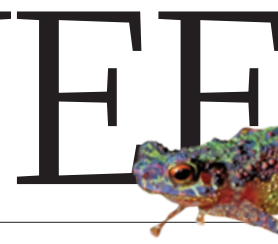

WORLD VIEW China must improve the quality of its research $\mathbf{p . 2 6 7}$
7 glorious Technicolour toad resurfaces in Borneo jungle p.270

\title{
Don't blame the CIA
}

\section{Tales of fake vaccination drives are the least of Pakistan's public-health problems. A disjointed care system and lack of services are doing more damage.}

$\mathrm{T}$ he story is so far-fetched that it might just be true. According to newspaper reports, US spies this year conscripted a Pakistani doctor to run a fake vaccination campaign in the quiet city of Abbottabad, as part of a plot to uncover the hiding place of Osama Bin Laden. The Central Intelligence Agency (CIA) supposedly wanted to confirm the whereabouts of the United States' most-wanted terrorist before he was targeted by US special forces in a raid on the town in May (see Nature http://dx.doi.org/10.1038/news.2011.418; 2011).

Within days of the story's publication in UK newspaper The Guardian, the CIA was attacked by Pakistani doctors, public-health experts working in the country and Médecins Sans Frontières, a major aid agency based in Geneva, Switzerland. They warned that stories of the sham vaccination drive, which targeted hepatitis $B$, would reinforce conspiracy theories already circulating in Pakistan, and could drive up refusal rates for all vaccines - just when the country's efforts to eradicate polio through vaccinations are flagging.

The CIA has refused to confirm or deny the story, but the reaction to its supposed plot is telling. Pakistan's investment in health care is among the lowest in the world - just $2.6 \%$ of gross domestic product. Infant-mortality rates are high, and health-service coverage is poor. Against this desperate backdrop, few familiar with the nation's health system would doubt suggestions that a government doctor could be bought off by a foreign intelligence service to aid in an assassination plot. Nor are they likely to be surprised at the same doctor then having travelled to a major city, paid off low-level health-care workers and conducted a mass vaccination campaign without detection.

The scheme has hit a nerve because, until now, vaccinations have been among the few bright spots in Pakistan's health statistics. Too many children still go unprotected, but outright refusals of polio vaccine by parents account for just $6 \%$ of missed children, according to the United Nations Children's Fund. This is despite the anti-vaccine conspiracy theories that had been circulating long before stories of the CIA plot emerged. In recent years, vaccination rates for other diseases, such as measles, have been around $80-85 \%$, not far behind developed nations such as the United Kingdom.

That is not to understate the challenges. Polio virus is surging in Pakistan, and 2010 saw a $62 \%$ increase in cases over the previous year. This year, the World Health Organization has already reported 59 cases of children paralysed by the virus - almost double the number at this time last year. Many cases are in the Federally Administered Tribal Areas, a semi-autonomous region that is difficult to reach, in part because of ongoing military activity. But the southern city of Karachi has also seen an increase in polio cases, attributable in part to unvaccinated refugees arriving in the city after being displaced by last summer's flooding.

A report last month by the Independent Monitoring Board of the Global Polio Eradication Initiative in Geneva noted that Pakistan's broken health system is a major factor in the disease's resurgence. Leadership from the top is weak, and under this year's devolution of

the system to local governments, it looks set to become even weaker.

Meanwhile, reports from researchers on the ground suggest that the morale of the nation's army of 'volunteer' vaccinators, paid less than US $\$ 2$ a day, is flagging. The volunteers say that the people they are trying to help are increasingly hostile to their efforts, having been subjected to a decade of vaccination drives but offered few other health services.

The situation is similar to that in northern Nigeria, where vaccination rates have plummeted in the past decade because of strife and

\section{"Volunteers} say that the people they are trying to help are increasingly hostile to their efforts." armed conflict. Scare stories that vaccinaMuslims posed (and continue to pose) sig nificant obstacles to polio eradication. Trust is being rebuilt in Nigeria, in part by charities and the national government working with local leaders, but also through improvements in overall health care. For example, as incentives to allow vaccination, families were offered bed nets to deter mosquitoes carrying the much-feared disease malaria. Polio rates have been reduced by $95 \%$ over the past year, although much work remains.

The latest reports of a CIA-led vaccination plot are troubling and could complicate public-health campaigns in Pakistan at a key time. But they will not be a deciding factor in the war against polio and other preventable diseases. Pakistan's decrepit and failing health-care system poses a far greater threat. And it deserves as much attention.

\section{Growing pains}

It is time to update decades-old regulation of genetically engineered crops.

$\mathrm{R}$ esearchers at Scotts Miracle-Gro have a vision of a greener future. The lawn-care company, based in Marysville, Ohio, wants to develop a dwarf grass that needs less frequent maintenance than standard Kentucky bluegrass. But there is a catch: such grass is unlikely to stand up to weeds. No problem, the company reasons, it will make a dwarf grass that is resistant to herbicide to help homeowners to nip those weeds in the bud.

Development of this genetically modified (GM) Kentucky bluegrass made headlines this month when the US Department of Agriculture (USDA) told Scotts that it did not have the authority to regulate it (see page 274). As a result, Scotts is free to start selling its new crop without oversight.

The reason for this is historical. US regulation of GM crops relies 